\title{
Successful biliary stone removal after resolution of post-endoscopic sphincterotomy papillary stenosis using temporary covered metal stent placement
}

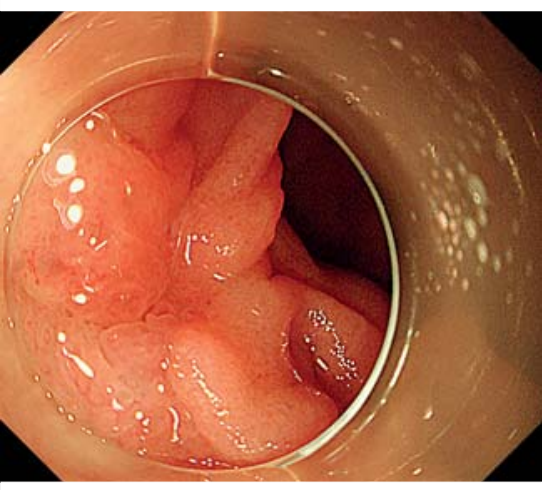

Fig. 1 Endoscopic image showing the post-endoscopic sphincterotomy scar on the papilla.

Although few studies have reported the frequency of papillary stenosis after endoscopic sphincterotomy (EST), serious complications such as bleeding and duodenal perforation are reported with repeated EST [1]. For benign biliary stenosis, the usefulness of temporary placement of a fully covered self-expandable metal stent (FCSEMS) is reported [2]. Herein, we describe successful biliary stone removal after resolution of postEST papillary stenosis using temporary placement of a dumbbell-shaped FCSEMS (BONASTENT M-Intraductal; Sci-Tech Inc., Seoul, South Korea), which has a central saddle portion with a diameter $2 \mathrm{~mm}$ less than that of the proximal and distal portions to prevent stent migration.

A 79-year-old man who underwent total gastrectomy for gastric cancer 30 years previously was admitted to our hospital because of a recurrent biliary stone. The patient had undergone single-balloon enteroscopy (SBE)-assisted EST with lithotripsy for biliary stones 4 months prior to the present admission. The latest SBE showed a post-EST scar on the papilla ( Fig.1); subsequent cholangiography showed an 8-mm biliary stone. Endoscopic papillary balloon dilation was performed using a $10-\mathrm{mm}$ balloon, but the

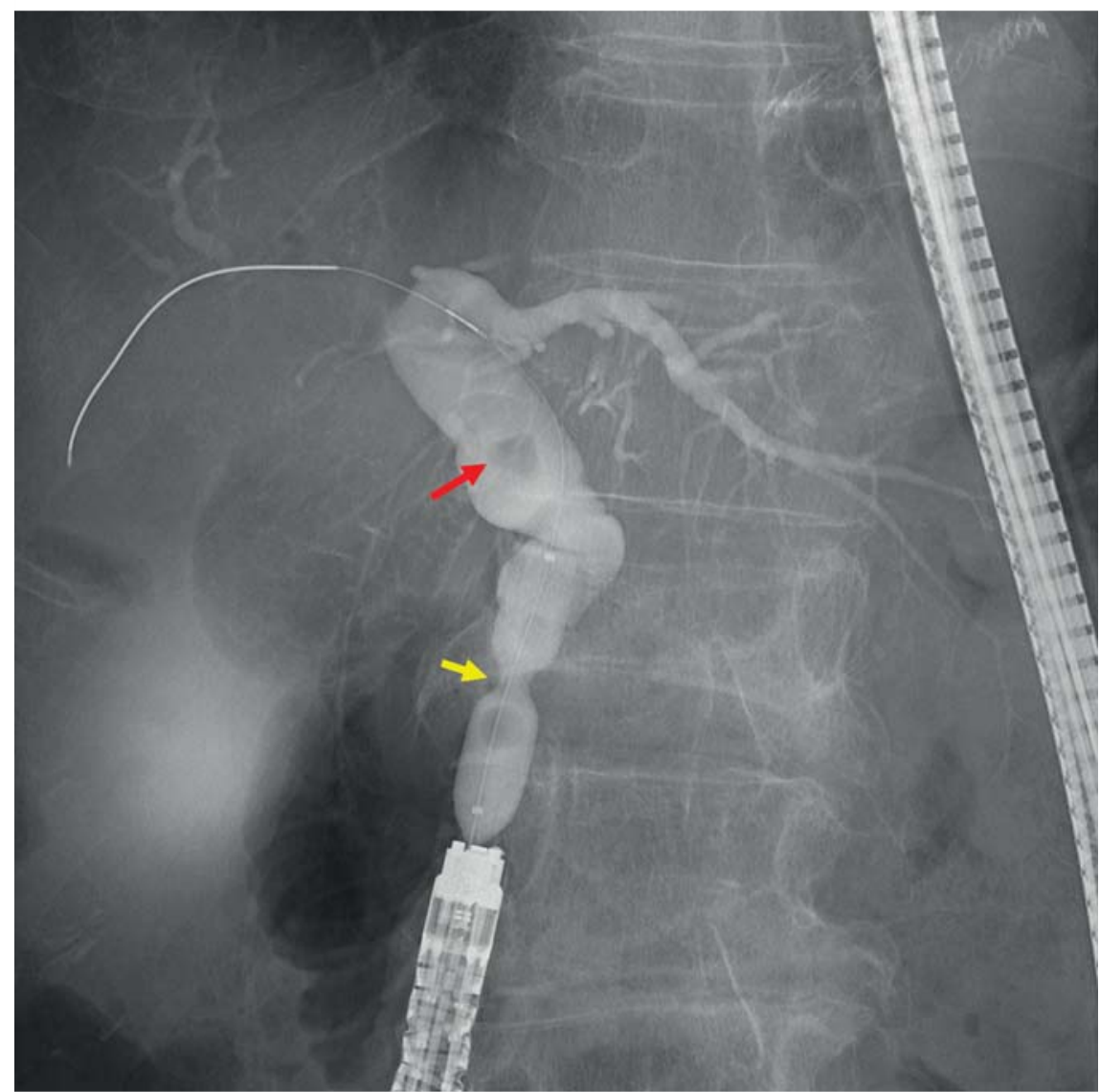

- Fig. 2 Cholangiogram showing an 8-mm stone in the common bile duct (red arrow). The papilla was hard and stenosed, and could only be dilated to $5 \mathrm{~mm}$ (yellow arrow) during endoscopic papillary balloon dilation using a $10-\mathrm{mm}$ balloon.

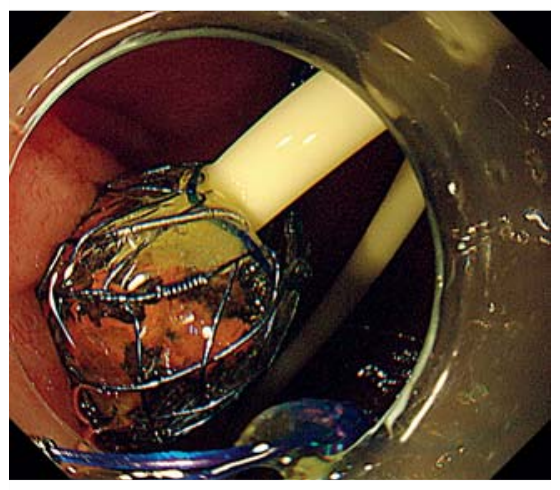

- Fig. 3 Endoscopic image showing a double-pigtail plastic stent placed through a dumbbell-shaped fully covered self-expandable metal stent that had been placed across the papilla.

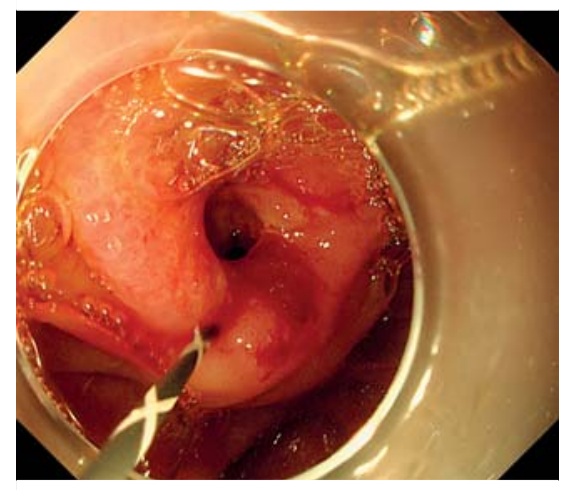

- Fig. 4 Endoscopic image 4 weeks later showing resolution of the stenosis after removal of the fully covered self-expandable metal stent. 


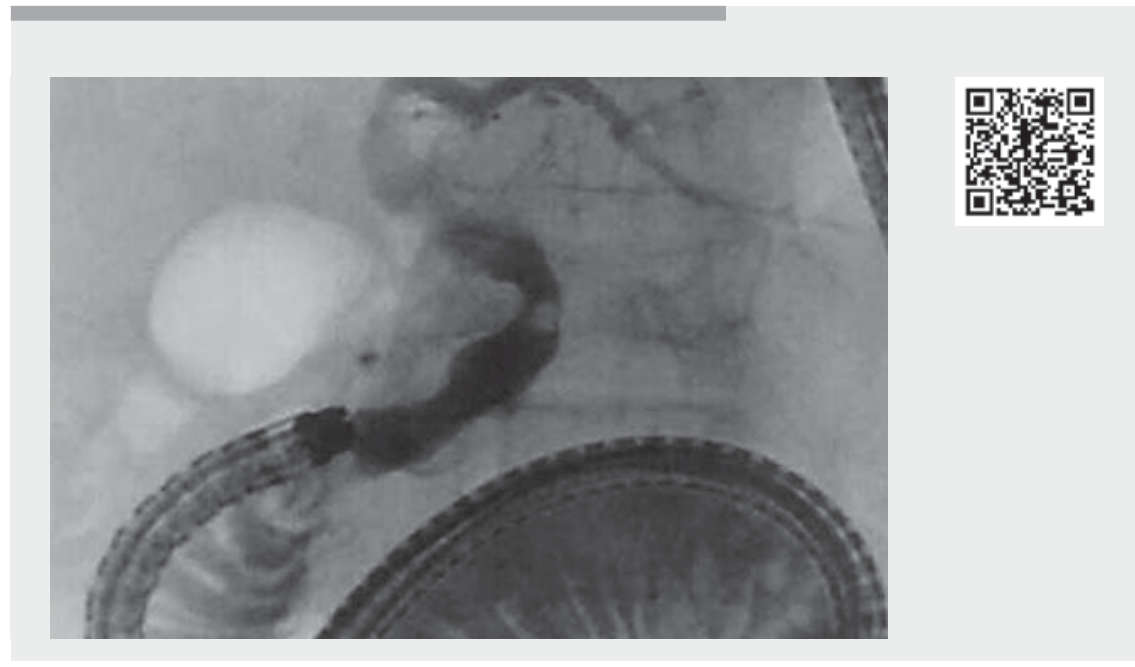

$\checkmark$ Video 1 Successful biliary stone removal after resolution of post-endoscopic sphincterotomy papillary stenosis using dumbbell-shaped covered metal stent placement.

[1] Elmi F, Silverman WB. Long-term biliary endoscopic sphincterotomy restenosis: incidence, endoscopic management, and complications of retreatment. Dig Dis Sci 2010; 55: 2102-2107

[2] Tringali A, Reddy DN, Ponchon T et al. Treatment of post-cholecystectomy biliary strictures with fully-covered self-expanding metal stents - results after 5 years of followup. BMC Gastroenterol 2019; 19: 214

\section{Bibliography}

Endoscopy 2022; 54: E210-E211

DOI 10.1055/a-1486-6659

ISSN 0013-726X

published online 12.5 .2021

(c) 2021. Thieme. All rights reserved.

Georg Thieme Verlag KG, Rüdigerstraße 14,

70469 Stuttgart, Germany

post-EST papilla was hard, stenosed, and could only be dilated to $5 \mathrm{~mm}$ ( $\mathbf{F i g} .2$ ). Lithotripsy was attempted but failed because the stone could not be grasped with a mechanical lithotripter. Therefore, an FCSEMS $(10 \mathrm{~mm} \times 4 \mathrm{~cm})$ was placed across the papilla for stenosis resolution. Finally, a double-pigtail plastic stent was placed in the FCSEMS to prevent stone impaction ( $\mathbf{F i g . 3}$ ). The patient was readmitted 4 weeks later for stone removal. After the FCSEMS was removed, the stenosis was found to have resolved ( Fig.4) and the stone was successfully removed using a retrievable balloon catheter ( $\vee$ Video 1 ).

Our procedure was safe and could be useful for troubleshooting when removal of biliary stones is difficult because of hard stenosis of the papilla after EST.

Endoscopy_UCTN_Code_TTT_1AR_2AZ

\section{Competing interests}

The authors declare that they have no conflict of interest.

\section{The authors}

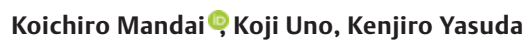
Department of Gastroenterology, Kyoto Second Red Cross Hospital, Kyoto, Japan

\section{Corresponding author}

\section{Koichiro Mandai, MD}

Department of Gastroenterology, Kyoto Second Red Cross Hospital, 355-5 Haruobicho, Kamigyo-ku, Kyoto 602-8026, Japan mndkchr@gmail.com

\section{ENDOSCOPY E-VIDEOS}

https:/|eref.thieme.de/e-videos

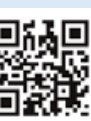

Endoscopy E-Videos is an open access online section, reporting on interesting cases and new techniques in gastroenterological endoscopy. All papers include a high quality video and all contributions are freely accessible online. Processing charges apply (currently EUR 375), discounts and wavers acc. to HINARI are available.

This section has its own submission website at https://mc.manuscriptcentral.com/e-videos 